\title{
Papers
}

\section{Patients' perspectives on electroconvulsive therapy: systematic review}

\author{
Diana Rose, Til Wykes, Morven Leese, Jonathan Bindman, Pete Fleischmann
}

\begin{abstract}
Objective To ascertain patients' views on the benefits of and possible memory loss from electroconvulsive therapy.

Design Descriptive systematic review.

Data sources Psychinfo, Medline, Web of Science, and Social Science Citation Index databases, and bibliographies.

Study selection Articles with patients' views after treatment with electroconvulsive therapy.

Data extraction 26 studies carried out by clinicians and nine reports of work undertaken by patients or with the collaboration of patients were identified; 16 studies investigated the perceived benefit of electroconvulsive therapy and seven met criteria for investigating memory loss.

Data synthesis The studies showed heterogeneity. The methods used were associated with levels of perceived benefit. At least one third of patients reported persistent memory loss.

Conclusions The current statement for patients from the Royal College of Psychiatrists that over 80\% of patients are satisfied with electroconvulsive therapy and that memory loss is not clinically important is unfounded.
\end{abstract}

\section{Introduction}

Electroconvulsive therapy is generally indicated for depression that is resistant to treatment. The procedure, which involves the application of electrodes to the head to induce a convulsion, is carried out under general anaesthetic. Although electroconvulsive therapy is less commonly used today than in the past, over 11000 patients receive it in England annually. ${ }^{1}$ Nearly one fifth of patients receive treatment under a special section of the Mental Health Act 1983.

The Royal College of Psychiatrists' fact sheet states that more than eight out of 10 depressed patients who receive electroconvulsive therapy respond well. " "Electroconvulsive therapy is the most effective treatment for severe depression and people ... report that it makes them feel 'like themselves again' or that 'life is worth living."'" Although reviews on attitudes to electroconvulsive therapy in the 1980 s concluded that patients found treatment beneficial and that they were satisfied with it, this is currently opposed by individual patients and groups. ${ }^{3}{ }^{4}$ We aimed to examine the sources of this controversy and to assess the debated distinctions between efficacy, effectiveness, and satisfaction. ${ }^{5}$ Efficacy is restricted to what can be measured in a controlled clinical trial, often over a short period. It will not necessarily predict the effectiveness of a treatment in a real life situation, still less will it predict satisfaction. For instance, a systematic review of randomised controlled trials investigated evidence of the efficacy of electroconvulsive therapy as measured by symptom scales completed by a mental health professional. ${ }^{6}$ But these ratings may not be the same as perceptions of relief of symptoms by patients themselves. For example, in one study similar numbers of patients were regarded as improved by themselves and by health professionals, but in $20 \%(n=13)$ of cases these were different individuals. ${ }^{7}$

Patients' perceptions of benefit are likely to be based on broader considerations than just the relief of symptoms. They may take into account the amount and length of time symptoms are relieved (clinical benefit) as well as any side effects. One side effect is memory loss. The Royal College of Psychiatrists' fact sheet states that while memory of recent events may be affected by electroconvulsive therapy, "in most cases this memory loss goes away within a few days or weeks although some patients continue to experience memory problems for several months. As far as we know, electroconvulsive therapy does not have any long term effects on your memory or intelligence." Some patients, however, report severe and longlasting memory losses after electroconvulsive therapy, and these will influence decisions on the risks and benefits of treatment.

Despite these disagreements there has been little systematic study of patients' views about the effectiveness and safety of electroconvulsive therapy. We aimed to ascertain patients' attitudes on the perceived benefit of treatment, as distinct from clinically rated outcome, and reported memory loss after treatment.

\section{Methods}

We searched the databases Psychinfo, Medline, Web of Science, and the Social Science Citation Index for papers and reports of patients' views on treatment with electroconvulsive therapy (see bmj.com for search terms). Bibliographies were also hand searched. Articles were excluded that concerned lay or
Editorial by Geddes and Carney

Service User

Research

Enterprise, PO34

Institute of

Psychiatry, De

Crespigny Park,

London SE5 8AF

Diana Rose

senior researcher

Pete Fleischmann

researcher

Department of

Psychology, Institute

of Psychiatry

Til Wykes

professor

Health Services

Research

Department,

Institute of

Psychiatry

Morven Leese

statistician

Jonathan Bindman

senior lecturer

Correspondence to:

D Rose

d.rose@iop.kcl.ac.uk

bmj.com 2003;326:1363

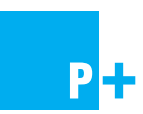

Search terms appear on bmj.com 
professional opinion, children or adolescents, or where not all the patients had received treatment.

Of the 27 papers identified, 26 were authored by academics or researchers and conducted in psychiatric facilities. A reference group enabled us to identify nine reports written either by patients or in collaboration with them. The work of Communicate, the user group at the Maudsley hospital, is awaiting publication, but we had access to its raw data. Although our searches included global sources, articles written by patients were confined to the United Kingdom in all but one case.

\section{Analysis}

We calculated the proportion of patients with positive responses to questions on effectiveness of treatment and the $95 \%$ confidence intervals. Positive responses were defined as an affirmative response to the statements "electroconvulsive therapy is helpful" or "I would have electroconvulsive therapy again." A Forrest plot was produced on the raw (proportion) scale as to whether electroconvulsive therapy was considered helpful, with normal approximation standard errors.

The research studies were rated on four methodological variables. These were selected from either previous research (setting and interviewer), preliminary analysis of the data (interval between treatment and interview), or the social science literature. ${ }^{8}$

\section{Interval between treatment and interview}

We considered the interval between treatment and interview because the benefits of treatment may be short lived and side effects only apparent later. The scores were: 0 for during course of treatment or maintenance treatment; 1 for within four weeks or predischarge; 2 for 1-6 months; and 3 for more than six months.
Number of questions

As a few brief questions are likely to produce less engagement than a more exploratory list of questions, we scored: 1 for five or less questions; 2 for 6 -14 questions; and 3 for 15 or more questions.

\section{Complexity of interview}

With simple response options there was less scope for patients to express their opinions whereas multiple choice questions or semistructured interviews allowed more complex opinions to be recorded. The scoring system was: 1 for dichotomous responses; 2 for simple Likert scales; 3 for complex Likert scales or multiple choice; and 4 for a semistructured interview.

\section{Setting of interview and status of interviewer}

Conducting an interview has been shown to influence the willingness of patients to be critical about services. ${ }^{9}$ They are more likely to be critical when interviewed by a fellow patient in a neutral setting. Because the setting and status are always highly correlated, we amalgamated them into one category. The scoring system was: 1 for inpatients; 2 for same hospital or treating doctor; 3 for non-treating doctor or at home; 4 for day care or voluntary sector; and 5 for source independent of health services, and choice of setting.

Logit models were fitted to assess associations between positive responses and methodological characteristics and the distinction between clinical and patient studies. SPSS version 10 and Stata version 7 were used for the analyses.

\section{Results}

In 16 studies patients were asked if they found electroconvulsive therapy helpful and in 12 studies they were

Table 1 Details of perceived benefit of electroconvulsive therapy, date, sample size, and four scored methodological variables of studies eliciting patients' views on treatment. Values are numbers (percentages; $95 \%$ confidence intervals) of patients unless stated otherwise

\begin{tabular}{|c|c|c|c|c|c|c|c|c|}
\hline \multirow[b]{2}{*}{ Study } & \multirow[b]{2}{*}{ Country } & \multirow[b]{2}{*}{ Sample size } & \multicolumn{2}{|c|}{ Perceived benefit of treatment } & \multicolumn{4}{|c|}{ Methodological variables } \\
\hline & & & Helpful & Would have again & $\begin{array}{l}\text { Interval since } \\
\text { treatment }^{*}\end{array}$ & $\begin{array}{c}\text { No of } \\
\text { questions† }\end{array}$ & $\begin{array}{l}\text { Complexity of } \\
\text { interview } \neq\end{array}$ & $\begin{array}{c}\text { Setting or } \\
\text { interviewer§ }\end{array}$ \\
\hline Freeman and Kendell $1980^{10}$ & United Kingdom & 166 & $129(78 ; 71$ to 84$)$ & $98(59 ; 51$ to 67$)$ & 3 & 3 & 4 & 2 \\
\hline Hughes et al $1981^{7}$ & United Kingdom & 72 & $59(83 ; 73$ to 91$)$ & $52(72 ; 60$ to 82$)$ & 2 & 3 & 2 & 2 \\
\hline Kerr et al $1982^{11}$ & Australia & 88 & $64(73 ; 62$ to 82$)$ & Not available & 2 & 3 & 1 & 3 \\
\hline Aperia $1986^{12}$ & Norway & 30 & $21(70 ; 51$ to 85$)$ & $19(63 ; 44$ to 80$)$ & 3 & 2 & 3 & 2 \\
\hline Benbow $1988^{13}$ & United Kingdom & 54 & $39(73 ; 58$ to 84$)$ & $37(69 ; 54$ to 80$)$ & 1 & 3 & 2 & 1 \\
\hline Szuba et al $1991^{14}$ & United States & 25 & $19(76 ; 55$ to 91$)$ & $18(72 ; 51$ to 88$)$ & 1 & 1 & 2 & 1 \\
\hline Rogers and Pilgrim $1993^{15} q$ & United Kingdom & 231 & $99(43 ; 36$ to 50$)$ & Not available & 3 & 3 & 3 & 4 \\
\hline Riordan et al $1993^{16}$ & United Kingdom & 37 & $21(56 ; 39$ to 73$)$ & $25(67 ; 50$ to 82$)$ & 2 & 3 & 4 & 3 \\
\hline Pettinati et al $1994^{17}$ & United States & 78 & Not available & $76(98 ; 91$ to 100$)$ & 1 & 1 & 1 & 1 \\
\hline $\begin{array}{l}\text { United Kingdom Advocacy } \\
\text { Network } 1995^{18} \rrbracket\end{array}$ & United Kingdom & 308 & $92(30 ; 25$ to 36$)$ & $55(18 ; 14$ to 23$)$ & 3 & 3 & 2 & 5 \\
\hline Mental Health Foundation $1997^{19} \rrbracket$ & United Kingdom & 107 & $32(30 ; 21$ to 40$)$ & Not available & 3 & 2 & 3 & 5 \\
\hline Bernstein et al $1998^{20}$ & United States & 52 & $43(83 ; 70$ to 92$)$ & $41(79 ; 65$ to 89$)$ & 0 & 2 & 1 & 1 \\
\hline ECT Anon $1998^{21} \emptyset$ & United Kingdom & 200 & $58(29 ; 23$ to 36$)$ & Not available & 3 & Not given & Not given & 5 \\
\hline Wheeldon et al $1999^{22}$ & United Kingdom & 150 & $121(81 ; 74$ to 87$)$ & $115(77 ; 70$ to 84$)$ & 1 & 1 & 1 & 1 \\
\hline Goodman et al $1999^{23}$ & United States & 24 & Not available & 20 (82; 63 to 95$)$ & 0 & 3 & 1 & 2 \\
\hline Pedler (MIND) $2000^{24} \|$ & United Kingdom & 418 & $150(36 ; 31$ to 41$)$ & Not available & 3 & 3 & 3 & 4 \\
\hline $\begin{array}{l}\text { Manic Depression Fellowship } \\
2002^{25 q}\end{array}$ & United Kingdom & 97 & $29(30 ; 21$ to 40$)$ & Not available & 3 & 3 & 3 & 5 \\
\hline Communicatef & Pending & 45 & $20(44 ; 30$ to 60$)$ & $18(41 ; 26$ to 56$)$ & 2 & 3 & 1 & 4 \\
\hline
\end{tabular}

${ }^{\star} 0=$ During course or maintenance electroconvulsive therapy; $1=$ within four weeks or predischarge; $2=1-6$ months; $3=$ more than six months.

$\dagger 1=$ Five questions or less; $2=6-14$ questions; $3=15$ or more questions.

¥1=Dichotomous; 2=simple Likert scale; $3=$ complex Likert scale or multiple choice; 4=semistructured interview.

$\S 1=$ Inpatient; $2=$ same hospital or same treating doctor; $3=$ non-treating doctor or at home; $4=$ voluntary or collaborative, day care or choice; $5=$ source independent of health services, choice of setting.

qPatient study. 
asked if they would have the treatment again (table 1). The level of positive responses varied widely between studies (tests for heterogeneity: $\chi^{2}=370, \mathrm{P}<0.001$, for treatment helpful, $\chi^{2}=256, \mathrm{P}<0.001$ for would have treatment again). The Forrest plot for "helpful" shows that the patient led and collaborative studies report the lowest levels of positive responses; there was, however, an overlap in the confidence intervals (figure and table 1).

A funnel plot showed no evidence of publication bias among the clinical studies. No systematic relation was found between perceived benefit and the country, or region of the United Kingdom, where the research was undertaken.

\section{Methodological variables}

The number of questions, complexity of the interviews, and the interval before interview were intercorrelated (between number of questions and both the other two variables $r=0.54$, between interval and complexity $\mathrm{r}=0.75$ ). The clinical studies tended to use fewer questions, less complex schedules, and a shorter interval, although the difference in complexity was not significant (see table 1).

Studies where the interviews were conducted soon after treatment, in hospital settings, by the treating doctor, were more likely to report positive views of electroconvulsive therapy (table 2). Studies with low complexity schedules, few questions, and a short interval were also associated with high perceived benefit. In the case of treatment considered helpful there was a clear hierarchy in setting, as coded from studies of inpatients (coded 1) to studies based in the community (coded 5).

When the analyses were repeated for the clinical studies alone, the effects were in the same direction and of a similar magnitude. Because of reduced sample sizes, fewer associations were significant. Within clinical studies, the number of questions remained significantly associated with treatment considered helpful, and complexity and interval were associated with whether the patient would have treatment again. In multivariate models, only setting remained significant.

\section{Persistent memory loss}

Of the 35 studies, 20 considered memory loss as a consequence of electroconvulsive therapy. Thirteen were excluded because data were not given or the interval between treatment and questions about memory loss was less than six months. In four of the remaining studies, respondents were asked specifically whether they had experienced persistent or permanent memory

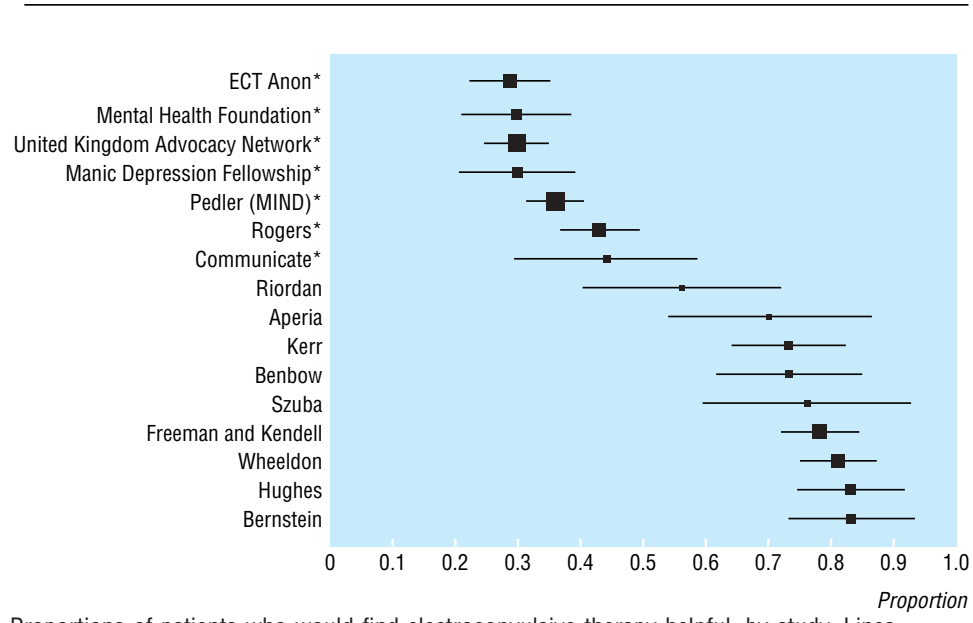

Proportions of patients who would find electroconvulsive therapy helpful, by study. Lines indicate approximate $95 \%$ confidence intervals; size of box indicates precision. *Patient study

Table 3 Numbers (percentages) of patients reporting memory loss, by study

\begin{tabular}{lcc} 
& \multicolumn{2}{c}{ Memory loss } \\
\cline { 2 - 3 } Study & Strict definition* & Loose definition† \\
\hline Freeman and Kendell $1980^{10}$ & $48 / 166(29)$ & $131 / 166(79)$ \\
\hline Kerr et al 1982 & $26 / 88(30)$ & - \\
\hline Pedler (MIND) $2000^{24} \ddagger$ & $176 / 418(42)$ & - \\
\hline Squire and Slater $1983^{26}$ & $17 / 31(55)$ & - \\
\hline Pettinati et al $1994^{17}$ & - & $23 / 78(51)$ \\
\hline Communicate $\neq$ & - & $225 / 308(52)$ \\
\hline United Kingdom Advocacy Group $1995^{18} \ddagger$ & - &
\end{tabular}

*Persistent or permanent memory loss.

†Any memory loss reported.

†Patient study.

loss, and in four studies any reported memory problem was sought (one study reported on both; table 3).

The rate of reported persistent memory loss varied between $29 \%$ and $55 \%$, but, unlike levels of perceived benefit, the rate did not seem to depend on whether studies were clinical or patient based, with relatively high levels being reported by both types of study.

\section{Discussion}

The methods used to elicit patients' views on electroconvulsive therapy influence the reporting of perceived benefit and willingness to repeat treatment. Variation in levels of perceived benefit was also related to the source of the research. Patient led studies reported lower rates of perceived benefit than clinical studies. This might be attributed to a selection bias,

Table 2 Associations between positive responses and methodological variables of patients' responses to electroconvulsive therapy. Values are odds ratios (95\% confidence intervals) unless stated otherwise

\begin{tabular}{|c|c|c|c|c|}
\hline Study characteristic & Treatment helpful $(n=16)$ & $P$ value & Would have treatment again $(n=12)$ & $P$ value \\
\hline \multicolumn{5}{|l|}{ Schedule*: } \\
\hline Interval between treatment and interview (scale 0-3) & 0.542 (0.491 to 0.597$)$ & $<0.001$ & $0.482(0.422$ to 0.551$)$ & $<0.001$ \\
\hline Complexity of interview (scale 1-4) & $0.804(0.733$ to 0.880$)$ & $<0.001$ & 0.918 (0.815 to 1.035$)$ & 0.161 \\
\hline No of questions (scale 1-3) & $0.353(0.288$ to 0.433$)$ & $<0.001$ & 0.508 (0.432 to 0.597$)$ & $<0.001$ \\
\hline \multicolumn{5}{|l|}{ Settingt: } \\
\hline Same hospital or treating doctor & 0.861 (0.592 to 1.253$)$ & 0.435 & $0.727(0.529$ to 1.017$)$ & 0.063 \\
\hline Non-treating doctor or some at home & $0.311(0.154$ to 0.629$)$ & $<0.001$ & 0.863 (0.419 to 1.773$)$ & 0.688 \\
\hline Collaborative & 0.198 (0.137 to 0.285$)$ & $<0.001$ & 0.276 (0.146 to 0.530$)$ & $<0.001$ \\
\hline Patient led & $0.124(0.092$ to 0.169$)$ & $<0.001$ & $0.090(0.063$ to 0.129$)$ & $<0.001$ \\
\hline
\end{tabular}

${ }^{*}$ Per unit increase in scale.

tCompared with inpatient. 
with patient studies only selecting people who were antagonistic to treatment. The study by Communicate, the user group at the Maudsley Hospital, is, however, a prospective one, where the interview schedule was clearly stated to come from a patient group. This study still reports lower rates of satisfaction than any of the clinical studies, indicating that even with a prospective design, patient led or collaborative research finds lower rates of satisfaction with treatment. Our findings suggest the difference may be attributed to a tendency for clinical studies to take place soon after treatment, to use medical assessors in clinical settings, and to use brief questionnaires with low complexity for responses.

Qualitative data collected as part of a wider review supports the above conclusions but show, in addition, how patients' views on electroconvulsive therapy are often complex. These data illuminate the way in which patients make decisions about electroconvulsive therapy by weighing the risks and benefits of treatment. Most of the studies we reviewed used simple response categories that did not allow this complex trade-off and other attitudes to be described. One hypothesis is that many patients are not simply for or against the treatment or even are neutral about it. The concept of satisfaction and its measurement are also subject to these criticisms of oversimplification. Future research should include qualitative measures with representative samples of patients who have received electroconvulsive therapy.

Electroconvulsive therapy is a complex intervention comprising many stages and the involvement of many staff. Patients may have varying views about these different stages. As the literature we reviewed relied on global ratings, however, it was not possible to investigate each stage independently. The exception was the information and consent stage, which will be reported later.

\section{Memory loss}

Although the studies did not use consistent definitions or standardised ratings for memory loss, levels were between $29 \%$ and $79 \%$. The levels were not determined by whether studies were clinician led or patient led, but the two types of study did differ in their analyses and interpretation of findings. Patient led research typically presents numerical results and illustrates these with quotations to show what the data mean in terms of patients' lives, whereas clinical researchers tend to undertake further statistical analysis of the data, sometimes ignoring the original data. For example, one study asked participants to assess the statement that "electroconvulsive therapy permanently wipes out large parts of memory."11 The study then reported that people who had never received treatment were more likely to endorse this statement than those who had received it. It did not, however, comment on the finding that one third of those who had received treatment agreed with the strongly worded statement.

Another study controlled for depression in the analyses and found that memory loss continued to be significant. ${ }^{27}$ Nonetheless, the authors concluded that long term memory loss was an important problem for only a small group of people and were doubtful about the causative role of electroconvulsive therapy.

The findings relate to the experience of persistent memory loss. Routine neuropsychological tests have

\section{What is already known on this topic}

Around 11000 people receive electroconvulsive therapy in England annually

Controversy exists as to whether treatment is beneficial and whether patients are satisfied with it

Patients' views have never been systematically reviewed

\section{What this study adds}

At least one third of patients report significant memory loss after treatment

Routine neuropsychological tests to assess memory do not address the types of memory loss reported by patients

Reported patient satisfaction with electroconvulsive therapy depends on the methods used to elicit a response

been used in studies of electroconvulsive therapy to establish objective measures of memory loss and concluded that there was no evidence of persistent memory loss. It would seem that these are the studies on which the Royal College of Psychiatrists based its findings. The studies, however, typically measure the ability to form new memories after treatment (anterograde memory). Reports by patients of memory loss are of the erasing of autobiographical memories or retrograde amnesia. Thus the risks reported by patients do not appear in clinical assessments.

\section{Controversy between medical opinion and patient} organisations

We found possible sources of controversy between professional bodies and some patients and patient organisations. The levels of perceived benefit differed between patient led and clinician led studies because different methods were used and because in many cases these methods did not allow an adequate description of the complexity of subjective experience. Even where findings, such as persistent memory loss, did not differ between patient led and clinician led studies, the interpretations may have differed radically. It is therefore not surprising that disputes can arise between professionals and patients and that organisations should emerge that provide support and a forum for those who feel their treatment has not been beneficial.

\section{Conclusion}

Although clinical trials concluded that electroconvulsive therapy is an effective treatment, ${ }^{6}$ measures of efficacy did not take into account all the factors that may lead patients to perceive it as beneficial or otherwise. Studies of treatment are needed that are able to investigate a range of outcomes valued by patients. Important among these are factors that impact on effectiveness and satisfaction. Also important is loss of autobiographical memory, which is widely described but insufficiently systematically investigated.

Contributors: All authors contributed to the design of the study and the interpretation of the findings and were involved in writing the paper. The data were collected by DR and PF and 
analysed by DR, TW, and ML. DR and PF have been recipients of electroconvulsive therapy. DR will act as guarantor for the paper. Competing interests: This paper is based on a report funded by a grant from the Department of Health, England. The Department of Health has given permission for publication but does not necessarily endorse the views contained in the paper.

1 Department of Health. Electroconvulsive therapy: survey covering the period from January 1999 to March 1999, England. Stat Bull Crown Copyright, 1999.

2 Royal College of Psychiatrists. Fact sheet on ECT. London: RCP, 1995.

3 Freeman C. Patients' attitudes towards ECT. Psychopharmacol Bull 1986;22:487-90.

4 Freeman CP, Cheshire KA. Attitude studies on electroconvulsive therapy. Convulsive Ther 1986;2:31-42.

5 Kennedy SH, Bagby RM. Efficacy and effectiveness in the antidepressant treatment of depression: beyond meta-analysis [editorial]. Can J Psychiatry 1996;4(10):609-10.

6 The UK ECT Review Group. Efficacy and safety of electroconvulsive therapy in depressive disorders: a systematic review and meta-analysis. Lancet 2003;354:1369.

7 Hughes J, Barraclough BM, Reeve W. Are patients shocked by ECT? $J R$ Soc Med 1981;74:283-5.

8 Kidder LH, Judd CM. Research methods in social relations, 5th ed. Published for the Society for the Psychological Study of Social Issues. New York: CBS Publishing, 1986

9 Polowycz D, Brutas M, Orvietto BS, Vidal J, Cipriana D. Comparison of patient and staff surveys of consumer satisfaction. Hosp Community Psychiatry 1993;44:589-91.

10 Freeman CP, Kendell RE. ECT: 1. Patients' experiences and attitudes. $\mathrm{Br}$ J Psychiatry 1980;137:8-16.

11 Kerr RA, McGrath JJ, O'Kearnery A, Price J. ECT: misconceptions and attitudes. Aust NZ J Psychiatry 1982;16:43-9.
12 Aperia B. Hormone pattern and post-treatment attitudes in patients with major depressive disorder given electroconvulsive therapy. Acta Psychiatr Scand 1986;73:271-4

13 Benbow SM. Patients views on electroconvulsive therapy on completion of a course of treatment. Convulsive Ther 1988;4:146-52.

14 Szuba MP, Baxter LR, Liston EH, Roy-Byrne P. Patients and family perspective of electroconvulsive therapy-correlation with outcome. Convulsive Ther 1991;7:175-83.

15 Rogers A, Pilgrim D. Service users' views of psychiatric treatments. Sociol Health Illness 1993;5:612-31.

16 Riordan DM, Barron P, Bowden MF. ECT: a patient-friendly procedure? Psychiatric Bull 1993;17:531-3.

17 Pettinati HM, Tamburello BA, Ruetsch CR, Kaplan FN. Patient attitudes toward electroconvulsive therapy. Psychopharmacol Bull 1994,30:471-5.

18 United Kingdom Advocacy Network. ECT survey: the national experience. Sheffield: UKAN, 1995

19 Mental Health Foundation. Knowing our own minds. London: MHF, 1997.

20 Bernstein H, Beale M, Kellner CH. Patient attitudes about ECT after treatment. Psychiatric Ann 1998;28:524-7.

21 ECT Anon. Questionnaire results to March 1999. West Yorkshire: ECT Anon, 1999.

22 Wheeldon TJ, Robertson C, Eagles JM, Reid I. The views and outcomes of consenting and non-consenting patients receiving ECT. Psychol Med 1999;29:221-3.

23 Goodman JA, Krahn LE, Smith GE, Rummans TA, Pileggi TS. Patient satisfaction with electroconvulsive therapy. Mayo Clin Proc 1999;74:96771.

24 Pedler M. Shock treatment: a survey of people's experience of electro-convulsive therapy (ECT). London: MIND, 2000

25 Manic Depression Fellowship. Listening to our members. London: Manic Depression Fellowship, 2002.

26 Squire LR, Slater PC. Electroconvulsive therapy and complaints of memory dysfunction: a prospective three-year follow-up study. $\mathrm{Br} \mathrm{J}$ Psychiatry 1983;142:1-8.

27 Freeman CPL, Weeks D, Kendell RE. ECT: 11: Patients who complain. Br J Psychiatry 1980;137:17-25.

(Accepted 15 May 2003) 